\title{
LETTER
}

\section{Distribution and mineralogy of radioactive Cs in reservoir sediment contaminated by the Fukushima nuclear accident}

\author{
Yusuke AoI ${ }^{*}$, Keisuke FuKushi" ${ }^{* *}$, Taeko Itono*, Norio KitadaI ${ }^{* * * * * *}$, Kenji KashiwaYA**, \\ Hirohisa YAMADA ${ }^{\dagger}$, Tamao HATTA ${ }^{\ddagger}$ and Yuzo MANPUKU ${ }^{\star}$ \\ *Graduate School of Natural Science and Technology, Kanazawa University, \\ Kakuma-machi, Kanazawa, Ishikawa 920-1192, Japan \\ **Institute of Nature and Environmental Technology, Kanazawa University, \\ Kakuma-machi, Kanazawa, Ishikawa 920-1192, Japan \\ ***Earth-Life Science Institute, Tokyo Institute of Technology, 2-12-1E-1, Ookayama, \\ Meguro-ku, Tokyo, 152-8550, Japan \\ ${ }^{\dagger}$ Environmental Remediation Materials Unit, National Institute for Materials Science 1-1 Namiki, \\ Tsukuba, Ibaraki 305-0044, Japan \\ Japan International Research Center for Agricultural Sciences 1-1 Owashi, \\ Tsukuba, Ibaraki 305-8686, Japan
}

\begin{abstract}
This study investigated the distribution and mineralogy of radioactive Cs in a core sample from reservoir sediment affected by the Fukushima Daiichi Nuclear Power Plant accident. The sample was obtained 19 months after the accident from a reservoir in Iitate-mura, Fukushima Prefecture. The vertical concentrations of radioactive $\mathrm{Cs}$ in the sediment core varied little from the surface to $9 \mathrm{~cm}$ depth: $20-30 \mathrm{~Bq} / \mathrm{g}$ for ${ }^{137} \mathrm{Cs}$. The concentration decreased abruptly at depths greater than $9 \mathrm{~cm}$. The radioactive Cs concentrations were particle-size dependent: finer particles exhibited higher concentrations of radioactive Cs. X-ray diffraction analyses of the size-fractionated sample revealed that the contribution of clay minerals (14 $\AA$ minerals, kaolin mineral and mica) increased concomitantly with the decrease of particle size, implying a close relation between radioactive Cs concentration and clay mineralogical compositions. Periodical airborne monitoring showed that the ${ }^{137} \mathrm{Cs}$ inventory in the reservoir catchment area decreased significantly with time after the accident. Results of a ${ }^{137} \mathrm{Cs}$ inventory in the reservoir sediment were almost identical to those for the catchment area immediately after the accident, but were significantly higher than those in the core sampling period. Results might indicate that the reservoir sediments serve as a sink for radioactive Cs.
\end{abstract}

Keywords: Radioactive Cs, Fukushima Daiichi Nuclear Plant, Reservoir sediment

\section{INTRODUCTION}

Radioactive Cs dispersed in the environment because of the Fukushima Daiichi Nuclear Power Plant (FDNPP) accident has come to cause severe environmental concern around the power plant. The radioactive Cs was deposited throughout an area to the northwest of FDNPP [First airborne monitoring by Ministry of Education, Culture, Sports, Science and Technology (MEXT) and U.S. Department of Energy (DOE), 2011; Yoshida and Takahashi, 2012]. Many reports have documented characteristics of the deposited radioactive $\mathrm{Cs}$ in soils and river sediments

doi:10.2465/jmps.130620c

K. Fukushi, fukushi@staff.kanazawa-u.ac.jp Corresponding author
(Ito et al. 2012; Kozai et al., 2012; Matsunaga et al., 2013; Qin et al., 2012; Tanaka et al., 2012). Ito et al. (2012) examined the distribution of radioactive Cs in some types of soils obtained in Iitate-mura, that is located in northwest from FDNPP and which was affected severely by the FDNPP accident. They showed that the radioactive Cs was retained in the top surface $(0-2 \mathrm{~cm})$ of the soils and that it was no more than $5 \mathrm{~cm}$ thick. They also reported that the radioactive Cs was distributed mainly in the fine fraction $(<75 \mu \mathrm{m})$ in soils. Similar characteristics of the radioactive Cs in the soils were observed in soil samples obtained in other regions (Kato et al., 2012; Matsunaga et al., 2013; Qin et al., 2012; Tanaka et al., 2012).

Agriculture, an important industry in areas near FDNPP, uses numerous storage reservoirs. Elucidating the 
characteristics of the radioactive Cs in reservoir sediments is important for the future use of the storage reservoirs, and for the prediction of the transport of the radioactive Cs in the local terrestrial environment. This study was conducted to characterize the radioactive Cs in reservoir sediments affected by FDNPP accident. The vertical and size distribution and mineralogy of radioactive Cs in sediment obtained 19 months after the accident were investigated using core sediments from the Hiso district, Iitatemura, Fukushima, Japan.

\section{STUDIED AREA, MATERIAL AND METHODS}

A short core was sampled from a storage reservoir (N37 $36^{\prime} 48^{\prime \prime}$ E140 $41^{\prime} 58^{\prime \prime}$ ) in Hiso district, Iitate-mura, Fukushima prefecture, Japan on 19 October 2012 (Figs. 1 and 2). The distance from the FDNPP to the studied reservoir is $35 \mathrm{~km}$. The reservoir has an area of $900 \mathrm{~m}^{2}$. The reservoir is shallow. The water depth of most of the northern part was low and less than $1 \mathrm{~m}$. The maximum depth of the reservoir was $1 \mathrm{~m}$ at the southern part of the reservoir. The reservoir has at least three inflows (Fig. 2). Among them, one inflow located in the northern part of the reservoir was dominant. Almost no water flowed at the other two inflows in October 2012 or March 2013. Two outflows exist for the reservoir (Fig. 2). An outflow located northeast of the reservoir is the main outflow. The other, located southeast of the reservoir, was designed for overflow from flood events. The $\mathrm{pH}$ and electric conductivity of the reservoir water were, respectively, 7.2 (at $13.6{ }^{\circ} \mathrm{C}$ ) and $26.8 \mathrm{mS} / \mathrm{m}$ in October 2012. The reservoir water was highly turbid. The bottom sediment surface was not observed by the naked eye in either October 2012 or March 2013. The catchment area is $290000 \mathrm{~m}^{2}$, comprising mainly field, forest, and bare areas. The ${ }^{137} \mathrm{Cs}$ inventory (the accumulation of ${ }^{137} \mathrm{Cs}$ per unit area) in the catchment area at one month after the accident (29 April
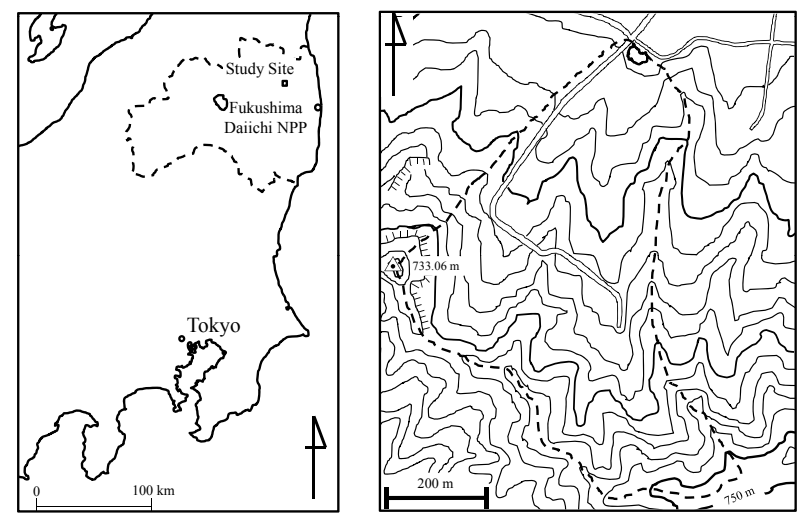

Figure 1. Locations and topographic map of the studied storage reservoir in Hiso district, Iitate-mura, Fukushima Prefecture.
2011; First airborne monitoring by MEXT and DOE, 2011) was $960-1200 \mathrm{kBq} / \mathrm{m}^{2}$. The measured values at two months before and after the core sampling (fifth and sixth airborne monitoring by MEXT, 2012 and 2013) were $400-690 \mathrm{kBq} / \mathrm{m}^{2}$.

The core sample was obtained with a gravity core sampler using an acrylic tube with $5.4 \mathrm{~cm}$ internal diameter at the southern part of the reservoir, where the water depth was $1 \mathrm{~m}$. The obtained core was $30 \mathrm{~cm}$ long. The core sediment was sliced at $1 \mathrm{~cm}$ intervals on site and freeze-dried in the laboratory. Radioactive concentrations of ${ }^{137} \mathrm{Cs}$ and ${ }^{134} \mathrm{Cs}$ of the samples were measured using a high-performance Germanium semiconductor detector (GEM-25-P4; Ortec) at the Radioisotope Laboratory for Natural Science and Technology, Kanazawa University. The concentrations of ${ }^{137} \mathrm{Cs}$ and ${ }^{134} \mathrm{Cs}$ at the 19 Oct. 2012 (sampling day) were calculated based on the half-life. Bulk mineralogy of the samples was examined in depth using X-ray diffraction (XRD, Ultima IV, 30kV, $20 \mathrm{~mA}$; Rigaku Corp.).

Surface samples from the top to $9 \mathrm{~cm}$ exhibiting high radioactive $\mathrm{Cs}$ concentrations were mixed to homogeneity in a plastic bag. The grain size distribution of the mixed sample was determined using a laser diffraction particle size analyzer (SALD-2200; Shimadzu Corp.). The mixed sample was also used for the ${ }^{137} \mathrm{Cs}$ radioactivity measurement and bulk XRD analysis. The mixed sample was fractionized into three size categories $(<2 \mu \mathrm{m}$ : clay, 2-64 $\mu \mathrm{m}$ : silt and $>64 \mu \mathrm{m}$ : sand). The clay $(<2 \mu \mathrm{m})$ fraction was separated by segmentation according to Stoke's law. The silt $(2-64 \mu \mathrm{m})$ and sand $(>64 \mu \mathrm{m})$ fractions were separated using water sieving with a $64 \mu \mathrm{m}$ sieve. Each fraction was used for the ${ }^{137} \mathrm{Cs}$ radioactivity measurement and XRD analysis.

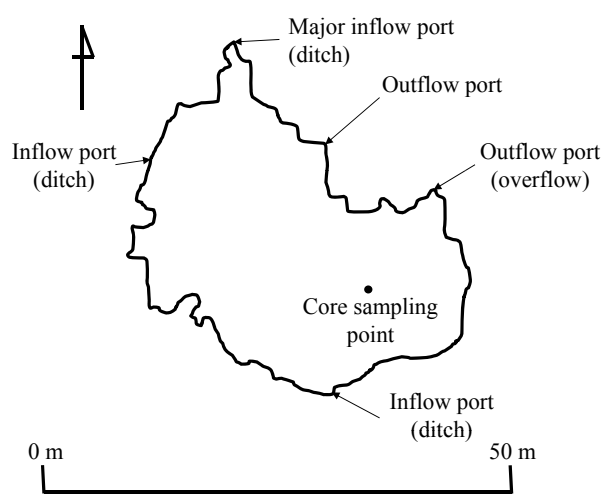

Figure 2. Map of the storage reservoir and location of the coring site. 


\section{RESULTS}

Sediment samples included quartz, plagioclase, amphibole, $14 \AA$ minerals, $7 \AA$ minerals, and mica from XRD patterns of the samples. No significant or systematic difference of the XRD patterns from the top to $30 \mathrm{~cm}$ depth, which indicates that the reservoir sediment is mineralogically homogeneous, at least up to $30 \mathrm{~cm}$ depth.

Figure 3 presents concentrations of ${ }^{134} \mathrm{Cs}$ and ${ }^{137} \mathrm{Cs}$ as a function of depth. The concentrations of ${ }^{137} \mathrm{Cs}$ were constant between $20-30 \mathrm{~Bq} / \mathrm{g}$ from the surface to $9 \mathrm{~cm}$ depth. The concentration decreased abruptly with depth greater than $9 \mathrm{~cm}$. The ${ }^{137} \mathrm{Cs}$ concentrations at depths greater than $15 \mathrm{~cm}$ were less than $0.5 \mathrm{~Bq} / \mathrm{g}$. The averaged ${ }^{134} \mathrm{Cs} /{ }^{137} \mathrm{Cs}$ corrected at March 2011 based on these half-lives was calculated as $0.96 \pm 0.02$, which was similar to those reported for the other samples affected by the FDNPP accident (Kato et al., 2012; Qin et al., 2012), confirming that the radioactive $\mathrm{Cs}$ in the sediment derived from the accident.

The ${ }^{137} \mathrm{Cs}$ concentration at the surface $9 \mathrm{~cm}$ mixed

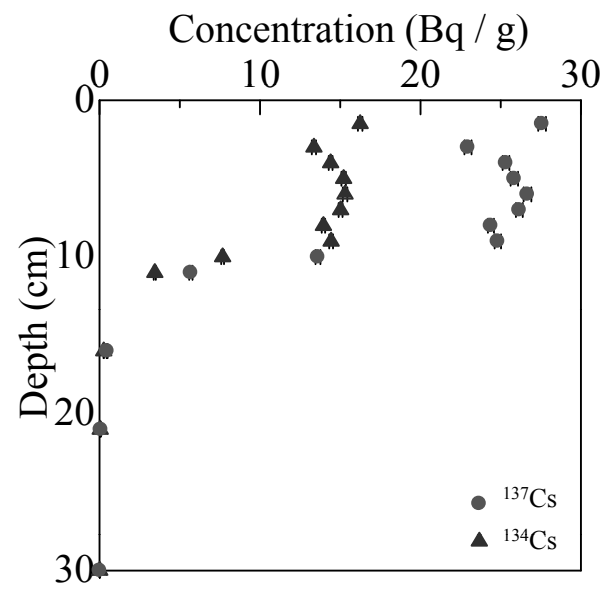

Figure 3. Variation of the concentrations of ${ }^{137} \mathrm{Cs}$ and ${ }^{134} \mathrm{Cs}$ in reservoir sediment with depth. Radioactive Cs concentrations were corrected at 19 Oct 2012 (sampling data) based on these halflives.

Table 1. Mineralogical compositions, volume fraction and ${ }^{137} \mathrm{Cs}$ concentration of sand, silt and clay from the surface $9 \mathrm{~cm}$ mixed sample.

\begin{tabular}{cccc}
\hline Sample & $\begin{array}{c}\text { Mineral } \\
\text { Component }\end{array}$ & ${ }^{137}$ Cs Conc. (Bq/g) & $\begin{array}{c}\text { Contents } \\
\text { (Vol\%) }\end{array}$ \\
\hline $\begin{array}{c}\text { Sand } \\
(>63 \mu \mathrm{m})\end{array}$ & $\begin{array}{c}\text { Quartz } \\
\text { Plagioclase } \\
\text { Amphibole }\end{array}$ & $8.82 \pm 0.19$ & 10 \\
$\begin{array}{c}\text { Quartz } \\
\text { Silt }\end{array}$ & $\begin{array}{c}\text { Amphibole } \\
(2-63 \mu \mathrm{m})\end{array}$ & $20.22 \pm 0.05$ & 81 \\
$\begin{array}{c}\text { Clay mineral } \\
(<2 \mu \mathrm{m})\end{array}$ & Clay Mineral & $54.84 \pm 0.60$ & 9 \\
\hline
\end{tabular}

samples was $24 \mathrm{~Bq} / \mathrm{g}$. The ${ }^{137} \mathrm{Cs}$ concentrations for clay $(<2 \mu \mathrm{m})$, silt $(2-64 \mu \mathrm{m})$ and sand $(>64 \mu \mathrm{m})$ fraction in the surface $9 \mathrm{~cm}$ mixed sample were, respectively, 54.5, 20.2 and $8.8 \mathrm{~Bq} / \mathrm{g}$ (Table 1). Almost $90 \%$ of the particles in the reservoir sediment have diameter less than $64 \mu \mathrm{m}$ categorized as silt or clay. Figure 4 portrays XRD patterns of clay $(<2 \mu \mathrm{m})$, silt $(2-64 \mu \mathrm{m})$ and sand $(>64 \mu \mathrm{m})$ fraction of the surface $9 \mathrm{~cm}$ mixed sample. The mineralogy clearly depended on the grain size. The clay fraction $(<2 \mu \mathrm{m})$ was composed of $14 \AA$ minerals, mica, and kaolin minerals which are categorizable as clay minerals with small contributions of quartz. The sand fraction $(>64 \mu \mathrm{m})$ was composed of quartz, plagioclase, and amphibole, which is categorizable as primary minerals with a small contribution of mica. The peaks of $14 \AA$ minerals and kaolin minerals in the sand fraction were not observed. The silt fraction was composed mainly of clay minerals, but included detectable peaks from primary minerals. The finer particles exhibited higher concentrations of ${ }^{137} \mathrm{Cs}$. Experimental studies have documented that the phyllosilicates with interlayer cations such as $14 \AA$ minerals such as smectite, vermiculate, and mica clay minerals exhibited sorption ability for Cs (Cornell, 1993), which implies that the radioactive $\mathrm{Cs}$ was retained selectively in the clay minerals, which are major constituent materials in the silt and clay fractions in the reservoir sediment.
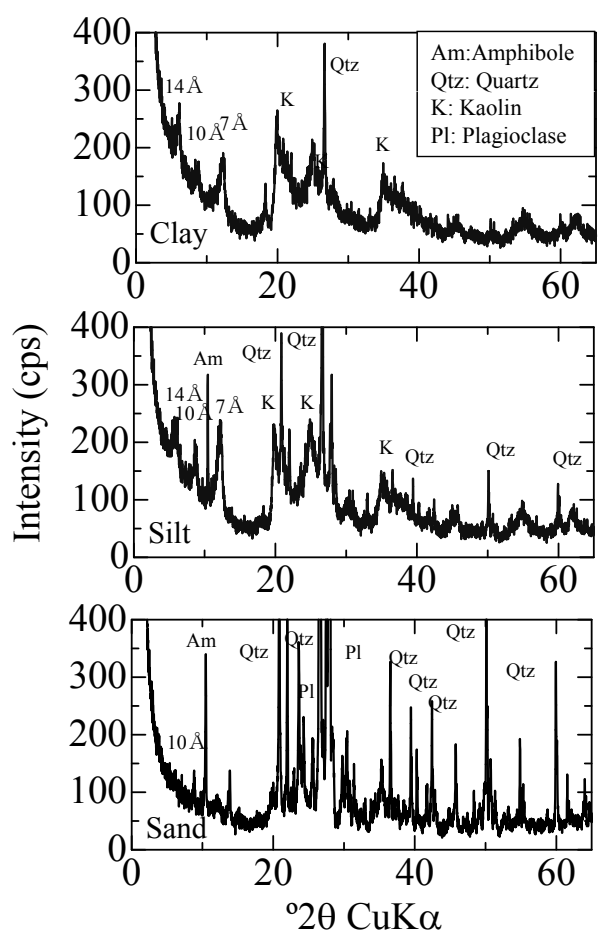

Figure 4. Bulk XRD patterns of clay $(<2 \mu \mathrm{m})$, silt $(2-64 \mu \mathrm{m})$, and sand $(>64 \mu \mathrm{m})$ fractions from the surface $9 \mathrm{~cm}$ mixed sample from reservoir sediment. 


\section{DISCUSSION}

Figure 5 presents changes of the ${ }^{137} \mathrm{Cs}$ inventory in the catchment area during April 2011 to March 2013 [MEXT and DOE 2011a; MEXT and DOE 2011b; MEXT 2011a; MEXT 2011b; MEXT 2012; MEXT 2013; Nuclear Regulation Authority, Japan (NRA), 2013]. The number of monitoring points in the catchment area was 10 or 11 . Plots in the figure represent the averaged inventories at the monitoring points. The upper and lower limits of each error bar respectively show maximum and minimum values in the catchment area. In April 2011, the ${ }^{137} \mathrm{Cs}$ inventory was greater than $1000 \mathrm{kBq} / \mathrm{m}^{2}$. It decreased abruptly to $600 \mathrm{kBq} / \mathrm{m}^{2}$ in July 2011. After July 2011, it decreased gradually with time and was $450 \mathrm{kBq} / \mathrm{m}^{2}$ in March 2013 . The line in the figure shows the calculated decrease of the ${ }^{137} \mathrm{Cs}$ inventory based on the half-life of ${ }^{137} \mathrm{Cs}$ from April 2011. The observed ${ }^{137} \mathrm{Cs}$ inventory after the July 2011 was clearly lower than that expected solely from the halflife from April 2011, which indicates that the radioactive $\mathrm{Cs}$ in this area most likely was removed from the catchment area because of some natural process such as precipitation or surface erosion, as described in MEXT reports $(2012,2013)$.

The ${ }^{137} \mathrm{Cs}$ inventory in the reservoir sediment obtained 19 months after the accident was calculated as 910 $\mathrm{kBq} / \mathrm{m}^{2}$ from a sum of the amounts of ${ }^{137} \mathrm{Cs}$ per unit area in different sediment layers of the obtained core (Fig. 5). The inventory is almost identical to that in the catchment area immediately after the accident $\left(1060 \mathrm{kBq} / \mathrm{m}^{2}\right)$ but it is significantly higher than those in the catchment area during the core sampling period $\left(400-600 \mathrm{kBq} / \mathrm{m}^{2}\right.$ during June 2012 - December 2012). Two interpretations can be made of the observed ${ }^{137} \mathrm{Cs}$ inventory in the sediment based on the characteristics of radioactive Cs in the sediment as described above.

The first is the preservation of the radioactive Cs di-

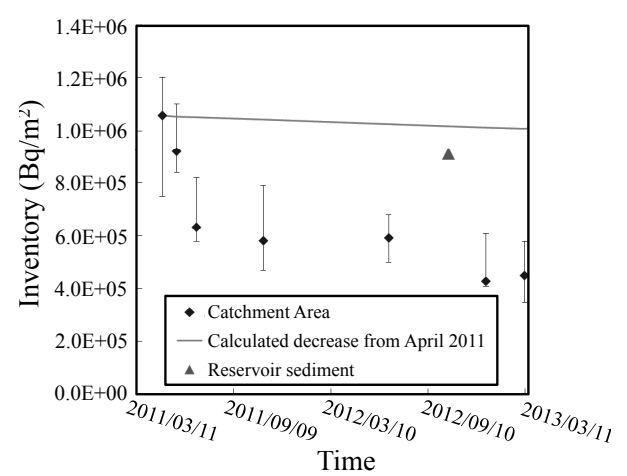

Figure 5. ${ }^{137} \mathrm{Cs}$ inventories of reservoir sediment based on the sum of the amounts of ${ }^{137} \mathrm{Cs}$ in each layer in the sediment core and the catchment area with time from airborne monitoring. rectly deposited in the reservoir sediments from the fallout. Tanaka et al. (2013) reported that immediately after the accident the radioactive $\mathrm{Cs}$ in airborne particles emitted from FDNPP were highly soluble in water. The radioactive Cs from airborne particles dissolved in the reservoir water. The reservoir water was highly turbid. Therefore, the dissolved radioactive Cs was scavenged by the clay minerals in the fine grained suspended matter. The suspended matter settled on the bottom. Once settled on the bottom, Cs generally remains in sediments (Ilus and Saxen, 2005). Although the radioactive Cs in the surrounding area was transported to downward by precipitation and surface erosion, that in the sediment remains in the reservoir.

The second is the accumulation of radioactive Cs in the reservoir sediment from the catchment area over time. The input of radioactive substances to lake basins from the Chernobyl accident was partly caused by direct deposition on the lake surface and partly by transport from the surrounding drainage area (Kansanen et al. 1991; Ilus and Saxen, 2005). In some small basins with short residence times, a large proportion of the fallout was washed out of the lake downstream (Meili et al. 1989; Kansanen et al. 1991). The storage reservoir is small compared with the lakes. It is likely that the radioactive Cs from the fallout was washed out from the reservoir. Thereby, the initial input of radioactive Cs in the reservoir sediment might be lower than that in the surrounding area. The materials in the sediments in the storage reservoir generally derive from the catchment area of the reservoir (Dearing, 1991; Ochiai et al. 2013). Therefore, it is plausible that the part of the eroded fine materials heavily contaminated with radioactive $\mathrm{Cs}$ in the catchment area has successively deposited on the reservoir bed. The radioactive Cs in the reservoir sediment was distributed at constant and high concentrations of 20-30 Bq/g from top surface to $9 \mathrm{~cm}$ depth. The depth profile is possibly attributable to the successive deposition of the contaminated fine particles from the catchment area, although further confirmation for the successive deposition is necessary.

The reservoir sediments might serve a role as a sink of the radioactive Cs, irrespective of the scenario. It is crucially important to elucidate the factors affecting the radioactive $\mathrm{Cs}$ accumulation in the reservoir sediments. In addition, careful monitoring of the radioactive $\mathrm{Cs}$ in the reservoir sediment should be conducted for the future use of the storage reservoir and for the prediction of the migration of radioactive $\mathrm{Cs}$ in the local terrestrial environment. 


\section{ACKNOWLEDGMENTS}

We thank a member of the staff of Iitate-mura village office, who provided permission to conduct research in Iitate-mura. Permission by the reservoir owner is also highly appreciated. The authors are grateful to members of the Iitate-mura research team led by NIMS-JAEA, for collaborative work. We also thank A. Yokoyama and Y. Nagamura of Kanazawa University for their help in use of the high-performance germanium semiconductor detector. Discussions with T. Murakami and S. Ochiai of Kanazawa University are also appreciated. The manuscript benefited from the comments of anonymous reviewers.

\section{REFERENCES}

Cornell, R.M. (1993) Adsorption of cesium on minerals: A review. Journal of Radioanalytical and Nuclear Chemistry, 171, 483500 .

Dearing, J.A. (1991) Lake sediment records of erosional processes. Hydrobiologia, 214, 99-106.

Ilus, E. and Saxén, R. (2005) Accumulation of Chernobyl-derived ${ }^{137} \mathrm{Cs}$ in bottom sediments of some Finnish lakes. Journal of Environmental Radioactivity, 82, 199-221.

Ito, K., Miyahara, H., Ujiie, T, Takeshima, T., Yokoyama, S., Nakata, K., Nagano, T., Sato, T., Hatta, T. and Yamada, H. (2012) Practical approach to decontamination of radioactive cesium-contaminated matter in agricultural region by improved wet classification and use of geomaterials. Transactions of the Atomic Energy Society of Japan, 11, 255-271 (Japanese with English abstract).

Kansanen, P.H., Jaakkola, T., Kulmala, S. and Suutarinen, R. (1991) Sedimentation and distribution of gamma-emitting radionuclides in bottom sediments of southrn Lake Päijänn, Finland, after the Chernobyl accident. Hydrobiologia, 222, 121-140.

Kato, H., Onda, Y. and Teramage, M. (2012) Depth distribution of ${ }^{137} \mathrm{Cs},{ }^{134} \mathrm{Cs}$, and ${ }^{131} \mathrm{I}$ in soil profile after Fukushima Dai-ichi Nuclear Power Plant Accident. Journal of Environmental Radioactivity, 111, 59-64.

Kozai, N., Ohnuki, T., Arisaka, M., Watanabe, M., Sakamoto, F., Yamasaki, S. and Jiang, M.Y., (2012) Chemical states of fallout radioactive Cs in the soils deposited at Fukushima Daiichi Nuclear Power Plant accident. Journal of Nuclear Science and Technology, 49, 473-478.

Matsunaga, T., Koarashi, J., Atarashi-Andoh, M., Nagao, S., Sato, T. and Nagai, H. (2013) Comparison of the vertical distributions of Fukushima nuclear accident radiocesium in soil before and after the first rainy season, with physicochemical and mineralogical interpretations. Science of Total Environment, 447, 301-314.

Meili, M., Rudebeck, A., Brewer, A. and Howard, J. (1989) Cs137 in Swedish forest lake sediments, 2 and 3 years after Chernobyl. In The Radioecology of Natural and Artificial Radionuclides (Feldt, W. Ed.). Verlag TUV Rheinland GmbH, Köln, Germany, 306-311.

MEXT (2011a) http://radioactivity.nsr.go.jp/en/contents/5000/418 2/24/1304797_0708e.pdf

MEXT (2011b) http://radioactivity.nsr.go.jp/en/contents/4000/ 3179/24/1270_1216.pdf

MEXT (2012) http://radioactivity.nsr.go.jp/en/contents/6000/5790/ 24/203_0928_14e.pdf

MEXT (2013) http://radioactivity.nsr.go.jp/en/contents/7000/ 6099/24/203_e_0301_18.pdf

MEXT and DOE (2011a) http://radioactivity.nsr.go.jp/en/contents/ 4000/3180/24/1304797_0506.pdf

MEXT and DOE (2011b) http://radioactivity.nsr.go.jp/en/contents/ 4000/3165/24/1304797_0616e.pdf

NRA (2013) http://radioactivity.nsr.go.jp/en/contents/7000/ 6936/24/270_0513.pdf

Ochiai, S., Nagao, S., Yamamoto, M., Itono, T., Kashiwaya, K., Fukui, K. and Iida, H. (2013) Deposition records in lake sediments in western Japan of radioactive Cs from the Fukushima Dai-ichi nuclear power plant accident. Applied Radiation Isotopes, 81, 366-370.

Qin, H.B., Yokoyama, Y., Fan, Q.H., Iwatani, H., Tanaka, K., Sakaguchi, A., Kanai, Y., Zhu, J.M., Onda, Y. and Takahashi, Y. (2012) Investigation of cesium adsorption on soil and sediment samples from Fukushima Prefecture by sequential extraction and EXAFS technique. Geochemical Journal, 46, 297-302.

Tanaka, K., Sakaguchi, A., Kanai, Y., Tsuruta, H., Shinohara, A. and Takahashi, Y. (2013) Heterogeneous distribution of radiocesium in aerosols, soil and particulate matters emitted by the Fukushima Daiichi Nuclear Power Plant accident: retention of microscale heterogeneity during the migration of radiocesium from the air into ground and river systems. Journal of Radioanalytical and Nuclear Chemistry, 295, 1927-1937.

Tanaka, K., Takahashi, Y., Sakaguchi, A., Umeo, M., Hayakawa, S., Tanida, H., Saito, T. and Kanai, Y. (2012) Vertical profiles of Iodine-131 and Cesium-137 in soils in Fukushima Prefecture related to the Fukushima Daiichi Nuclear Power Station Accident. Geochemical Journal, 46, 73-76.

Yoshida, N. and Takahashi, Y. (2012) Land-Surface Contamination by Radionuclides from the Fukushima Daiichi Nuclear Power Plant Accident. Elements, 8, 201-206.

Manuscript received June 20, 2013

Manuscript accepted November 7, 2013

Published online December 13, 2013

Manuscript handled by Tsutomu Sato 